\title{
Avaliação da eficiência de remoção de matéria orgânica em efluente sani- tário em função da idade do lodo de reator UASB: um estudo de caso
}

\author{
Ana Paula Nogueira das Neves ${ }^{\mathrm{a}}$, Dennis da Silva Ferreira ${ }^{\mathrm{a}}$, Douglas Azevedo Castro ${ }^{\mathrm{a}}$, \\ Grasiele Soares Cavallini ${ }^{\mathrm{a}^{*}}$ \\ a Universidade Federal do Tocantins (UFT), Brasil \\ *Autor correspondente (grasiele@uft.edu.br)
}

\section{N F O}

\section{Keywords}

degradation kinetics anaerobic degradation sludge time

\section{Palavras-chaves} cinética de degradação degradação anaeróbia detenção de lodo

\begin{abstract}
A B S T R A C T
Evaluation of organic matter removal efficiency in sanitary effluent as a function of age of UASB reactor sludge: a case study

In Brazil, one of the most widely used biological wastewater treatment processes is the UASB Upflow Anaerobic Sludge Blanket anaerobic reactor due to operating characteristics compatible with the prevailing climate and costs. relatively low maintenance. The present work evaluated the performance of the UASB reactor of a sewage treatment plant (ETE) located in the southern region of the state of Tocantins regarding the removal of organic matter as a function of age. The samples were characterized in relation to the physicochemical parameters: $\mathrm{pH}$, turbidity, total solids and Biochemical Oxygen Demand (BOD). Reactor monitoring took place over 4 months, and samples were collected monthly during this period, both in the reactor tributary and tributary. The efficiency of organic matter removal by the UASB reactor ranged from 52.5 to $93.0 \%$, and the highest value was observed only in the fourth month of collection, indicating that for sludge ages the process may not be efficient. The $\mathrm{pH}$ of the tributary and effluent presented similar values, close to neutrality and suitable for the anaerobic process. The total solids removal remained between 50 and $60 \%$, while the turbidity removal ranged from 70 to $80 \%$, which demonstrates that the affluent physicochemical conditions were adequate for the anaerobic treatment process. The degradation kinetics of organic matter by the reactor could be represented by a first order model, however, it was best represented by the equation $B O D=-0,0013 \cdot t^{3}+0,2786 \cdot t^{2}-18,801 \cdot t+625,55$.
\end{abstract}

\section{R E S U M O}

No Brasil, um dos processos de tratamento biológico de efluentes sanitários mais utilizados é o reator anaeróbio de fluxo ascendente e manta de lodo do tipo UASB (em inglês, Upflow Anaerobic Sludge Blan$k e t$ ), devido as suas características operacionais compatíveis com o clima predominante e os custos relativamente baixos de manutenção. O presente trabalho avaliou o desempenho do reator UASB de uma Estação de Tratamento de Esgoto (ETE) localizada na região sul do estado do Tocantins quanto à remoção de matéria orgânica em função da idade do lodo. Caracterizou-se as amostras em relação aos parâmetros físico-químicos: pH, turbidez, sólidos totais e Demanda Bioquímica de Oxigênio (DBO). O monitoramento do reator ocorreu ao longo de 4 meses, e as amostras foram coletadas mensalmente nesse período, tanto no afluente como no afluente do reator. A eficiência de remoção da matéria orgânica pelo reator UASB variou entre 52,5 e 93,0\%, e o maior valor foi observado apenas no quarto mês de coleta, o que indica que para idades de lodo inferiores o processo pode não ser eficiente. $\mathrm{O} \mathrm{pH}$ do afluente e efluente apresentaram valores semelhantes, próximo da neutralidade e adequados para o processo anaeróbio. A remoção de sólidos totais manteve-se entre 50 e $60 \%$, enquanto a remoção de turbidez variou entre 70 e $80 \%$, o que demonstra que as condições físico-químicas do afluente foram adequadas ao processo de tratamento anaeróbio. A cinética de degradação da matéria orgânica pelo reator pôde ser representada por um modelo de primeira ordem, no entanto, foi melhor representado pela equação $D B O=$ $-0,0013 \cdot t^{3}+0,2786 \cdot t^{2}-18,801 \cdot t+625,55$. 


\section{INTRODUÇÃO}

Segundo dados do Instituto Brasileiro de Geografia e Estatística (IBGE, 2019), estima-se que a população brasileira seja de 210 milhões de habitantes e apenas $52,4 \%$ desse total tem acesso à coleta de esgoto, dos quais $46 \%$ são tratados e, na região Norte do país, esse percentual é de apenas $22,6 \%$ (SNIS in ITB, 2019). O esgoto lançado nos corpos hídricos sem tratamento adequado é causador de degradação ambiental e induz ao aumento de doenças por veiculação hídrica e, por isso, tem relação direta com a qualidade de vida da população.

As Estações de Tratamento de Esgoto (ETE) são essenciais para o sucesso de um plano de saneamento, por terem como objetivo garantir a qualidade final dos efluentes e assim cumpra ao preconizado nas legislações ambientais vigente no país. Quando recebido na ETE, o esgoto (ou afluente) é submetido à uma série de processos físicos, químicos e biológicos, a depender do sistema construído. No caso do Brasil, há predominância de sistemas convencionais compostos por tratamento preliminar, primário, secundário e terciário (Lins, 2010).

Os tratamentos biológicos, fundamentado na degradação de matéria orgânica pela ação de microrganismos, são considerados uma das opções mais econômicas e eficientes de tratamento secundário de esgoto. Essa degradação pode ocorrer por meio de digestão aeróbia, digestão anaeróbia ou facultativa (Oliveira, 2014). Os processos anaeróbicos comparados aos aeróbios apresentam vantagens como a produção do biogás metano, o qual pode ser usado como fonte de energia e a menor produção de lodo (Leitão, 2006).

Os sistemas de tratamento anaeróbio ganham destaque à nível mundial e, principalmente no Brasil, por haver condições climáticas favoráveis ao funcionamento. Entre os diversos tipos de reatores utilizados em processos anaeróbios destaca-se o reator tipo UASB (em inglês, Upflow Anaerobic Sludge Blanket), que é considerado uma solução para o tratamento secundário de esgotos (Foresti, 2002). Este mecanismo é um tratamento biológico fundamentado na degradação de poluentes orgânicos complexos, pela ação de microrganismos, transformando-os em gases e água (Foresti et al., 1999).

Criado na década de 1970 na Holanda pelo cientista Lettinga e equipe, o reator UASB é uma combinação de processos físicos e biológicos, que basicamente requerem o contato da biomassa com o efluente em sistema anaeróbico para que haja ação digestória por parte das bactérias (Lima, 2006).

$\mathrm{O}$ reator UASB consiste em um tanque fechado, que possui uma coluna de escoamento ascendente, um leito de lodo, uma zona de digestão que se localiza no fundo e no topo um decantador precedido por um sistema de separação de gases (Oliveira in Neto, 2007).

No reator, o esgoto é distribuído uniformemente em fluxo ascendente no fundo do tanque, para que entre em contato com o leito de lodo e misture-se com o material orgânico e bactérias presentes, a fim de ocorrer a digestão anaeróbia. Conforme progridem as reações digestórias, o esgoto segue para o separador trifásico em que se separam as fases sólida, líquida e gasosa. (Pena, 2016).

Na parte inferior, isto é, no compartimento de digestão, está situado o leito de lodo. Nesta região o lodo é muito denso apresenta boas características de sedimentação, com grânulos que podem chegar a até $5 \mathrm{~mm}$ (Pontes e Chernicharo, 2009). Os grânulos de lodo exercem papel importante na eficiência do reator UASB, visto que esses materiais são a associação de microrganismos (bactérias e arqueas) que se formaram durante o processo de tratamento em um ambiente com um regime hidráulico de alta velocidade constante sem matriz de suporte (Abdelgadir et al., 2014).

Os reatores UASB contidos de manta de lodo apresentam várias vantagens como: necessita de pequena área instalação, simplicidade na construção, facilidade operacional, flexibilidade na operação podendo ser usando em pequena e grande escala, pouca produção de lodo, preservação da biomassa por longos períodos (Seghezzo et al., 1998).

O desempenho da estabilidade de reatores UASB é avaliado por meio de parâmetros físicoquímicos do afluente e efluente, e essas informações se constituem como ferramentas de monitoramento para otimização dos parâmetros de projeto, a operação do sistema e para predições de eficiência (Alves, 2015).

A cinética de digestão da matéria orgânica em reatores UASB é complexa e na literatura há poucos trabalhos que a descrevem, com isso, os estudos cinéticos têm se tornado essenciais para o desenvolvimento e operação desses reatores (Bhunia \& Ghangrekar, 2008).

Neste contexto, o presente estudo teve por objetivo realizar o estudo cinético da degradação de matéria orgânica, por meio da avaliação da eficiência de um reator UASB em função do tempo de detenção do lodo, utilizando o monitoramento de uma ETE dimensionada para tratar $900 \mathrm{~m}^{3} \cdot \mathrm{h}^{-1}$ de efluente sanitário.

\section{MATERIAL E MÉTODOS}

O estudo foi desenvolvido em ETE localizada na região sul do Estado do Tocantins inaugurada em 2009 com a capacidade inicial de tratamento de 180 
$\mathrm{m}^{3} \cdot \mathrm{h}^{-1}$ para população de 25 mil habitantes. Em 2017, ano de execução dessa pesquisa, a capacidade passou para $900 \mathrm{~m}^{3} \cdot \mathrm{h}^{-1} \mathrm{em}$ função do aumento populacional para 70 mil habitantes. Os meses de coleta compreenderam de junho a outubro do referido ano.

O sistema de tratamento da ETE é do tipo convencional, composto por tratamento preliminar (gradeamento, medição de vazão e desarenador) e tratamento secundário (reator UASB seguido de lagoa facultativa), na unidade há também um leito de secagem.

Coletou-se a amostras mensalmente em dois pontos (entrada e saída do reator), e a primeira ocorreu após 29 dias de detenção do lodo, a fim de caracterizar e comparar a qualidade do afluente e efluente e assim avaliar a eficiência do reator com base no tempo de detenção do lodo. As análises dos parâmetros físico-químicos seguiram o preconizado pela Standard Methods for the Examination of Water and Wastewater (Apha, 2012), conforme a tabela 01.

Tabela 01 - Parâmetros físico-químicos analisados.

\begin{tabular}{l|c}
\multicolumn{1}{c|}{ Parâmetros físico-químicos } & Método \\
\hline Demanda Bioquímica de Oxigênio - DBO $\left(\mathrm{mg}_{\mathrm{L}} \mathrm{L}^{-1}\right)$ & Manométrico \\
\hline $\mathrm{pH}$ & Potenciométrico $4500 \mathrm{H}^{+} \mathrm{B}$ \\
\hline Sólidos Totais $\left(\mathrm{mg} . \mathrm{L}^{-1}\right)$ & Gravimétrico 2540B \\
\hline Turbidez $(\mathrm{NTU})$ & Nefelométrico 2130 B \\
\hline
\end{tabular}

A cinética de degradação da matéria orgânica biodegradável foi estudada por meio de modelo cinético de primeira-ordem (Equação 1), frequentemente utilizado para o dimensionamento de ETE e estimar o desempenho do sistema em relação a matéria orgânica. A constante " $k$ " representa a taxa de estabilização da matéria orgânica presente no esgoto (Aragão, 2016).

$$
D B O t=D B O_{0} \cdot e^{-k t}
$$

Em que: $\mathrm{DBOt}=\mathrm{DBO}$ exercida no tempo $\mathrm{t}$ $\left(\mathrm{mg} . \mathrm{L}^{-1}\right) ; \mathrm{DBO} 0=\mathrm{DBO}$ no tempo $\mathrm{t}=\infty\left(\mathrm{mg} . \mathrm{L}^{-1}\right)$; $\mathrm{k}=$ coeficiente de remoção de matéria orgânica (d$1) ; \mathrm{t}=$ tempo de incubação (dias).

Para complementar o estudo cinético e otimizar o modelo resultante deste estudo, foi realizada uma Interpolação polinomial por Spline Cúbica. Este modelo foi construído a partir da suposição de que a curva de biodegradação da matéria orgânica pode ser representada conforme um polinômio de grau 3 , de acordo com a função abaixo:

$$
f(x)=a_{0}+a 1 x+a 2 x^{2}+a 3 x^{3}
$$

Dessa forma foi realizada uma adaptação do modelo para a aproximação da DBO em função do tempo, conforme a equação abaixo:

$$
D B O=D B O_{0}+k 1 t+k 2 t^{2}+k 3 t^{3}
$$

\section{RESULTADOS E DISCUSSÃO}

\section{Caracterização físico-quimica do afluente do re- ator UASDA}

Para caracterização físico-química do afluente do reator UASB foram utilizados os valores de quatro coletas, uma a cada mês (julho, agosto, setembro e outubro), o qual compreende os meses sem ocorrência de chuva no Estado do Tocantins conforme a Tabela 02. As análises foram realizadas em triplicata e a média de cada parâmetro foi utilizada para representar as características da amostra bruta

\begin{tabular}{|c|c|c|c|c|c|}
\hline \multirow[b]{2}{*}{ Parâmetro } & \multicolumn{5}{|c|}{ Data e horário da coleta } \\
\hline & $\begin{array}{c}04 / 07 / 2017 \\
12: 00\end{array}$ & $\begin{array}{c}\text { 07/08/2017 } \\
\text { 08:00 }\end{array}$ & $\begin{array}{c}\text { 11/09/2017 } \\
08: 00\end{array}$ & $\begin{array}{c}02 / 10 / 2017 \\
10: 00\end{array}$ & Valores médios \\
\hline $\mathrm{pH}$ & 7,0 & 6,5 & 7,6 & 7,0 & $7,0 \pm 0,4$ \\
\hline Turbidez (NTU) & $452,6 \pm 46,3$ & $1084 \pm 11,8$ & $473,3 \pm 48,7$ & $679,3 \pm 11,1$ & $672,5 \pm 253,6$ \\
\hline ST $\left(m g . L^{-1}\right)$ & $598,7 \pm 16,2$ & $809,2 \pm 51,0$ & $700,8 \pm 43,9$ & $738,3 \pm 25,0$ & $711,7 \pm 76,0$ \\
\hline $\mathrm{DBO}_{5}\left(\mathrm{mg} \cdot \mathrm{L}^{-1}\right)$ & $465 \pm 22,4$ & $905 \pm 11,0$ & $577 \pm 8,3$ & $540 \pm 25,0$ & $621,7 \pm 168,4$ \\
\hline
\end{tabular}
(afluente).

Tabela 02 - Média e desvio padrão dos parâmetros analisados. 


\section{Avaliação do pH}

$\mathrm{O} \mathrm{pH}$ das amostras do afluente apresentou pouca variação $(7,0$ a 7,6$)$ e manteve-se na faixa ideal para o processo anaeróbio (Tabela 03).

Tabela 03 - Valores de $\mathrm{pH}$ do afluente e afluente.

\begin{tabular}{|c|c|c|}
\hline & Efluente & $7,0 \pm 0,4$ \\
\hline \multirow{4}{*}{ 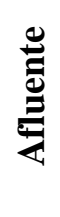 } & Julho & 7,1 \\
\hline & Agosto & 7,1 \\
\hline & Setembro & 7,2 \\
\hline & Outubro & 6,8 \\
\hline
\end{tabular}

Em todos os meses avaliados, as amostras de efluente apresentaram valores de $\mathrm{pH}$ próximos a neutralidade $(6,8$ a 7,2) e evidenciaram a existência de equilíbrio entre as etapas de conversão de matéria orgânica, de forma a não inibir a produção de metano pela excessiva produção de ácido graxos voláteis, que implicam na acidez do meio.

Comparado ao padrão estabelecido pela Resolução CONAMA n. 357 de 2005, complementada pela Resolução n. ${ }^{\circ} 430$ de 2011, o efluente para lançamento deve estar com $\mathrm{pH}$ na faixa de 5 a 9. Observa-se que em todos os meses de amostragem os valores de $\mathrm{pH}$ estiveram de acordo com a legislação em questão, contudo, ressalta-se que o local de coleta das amostras não é o fim do sistema e esse valor ainda poderia sofrer maiores variações.

$\mathrm{O}$ pH é um parâmetro essencial em estudos de saneamento ambiental, pois influencia na eficiência de tratamentos químicos e biológicos e, quando lançado no corpo hídrico, determinadas condições de $\mathrm{pH}$ podem favorecer a precipitação de compostos tóxicos e a solubilização de diversas espécies químicas que afetam o ecossistema aquático (Piveli, 2000).

De acordo com Sant'anna Júnior (2013), o pH é um parâmetro extremamente relevante no controle biológico, visto que a maioria das bactérias atuantes na degradação da matéria orgânica apresentam ótimo crescimento em valores de pH entre 5,5 e 8,5. Em ambientes anaeróbios, as bactérias das fases de hidrólise, acidogênese e acetogênese têm crescimento ótimo na faixa de $\mathrm{pH}$ de 5,0 a 6,0 e, no caso das metanogênicas, essa faixa varia de 6,6 a 7,4, que podem ser prejudicadas se houver elevada formação de ácidos voláteis. Neste sentido, é importante que o esgoto lançado não apresente valor de $\mathrm{pH}$ abaixo de 6,2 por um significativo período de tempo, ao considerar que quando a produção de gás metano se estabiliza, o $\mathrm{pH}$ passa a permanecer na faixa de 7,2 a 8,0 (Abdelgadir et al., 2014).

\section{Avaliação dos parâmetros físicos: Turbidez e Sólidos Totais (ST)}

A análise de turbidez do efluente propicia informações importantes quanto ao tempo de remoção do lodo, pois o excesso de lodo nos reatores UASB, além de acarretar na elevação da turbidez, diminui a eficiência do tratamento. A Figura 01 demonstra a variação observada durante os meses de estudo.

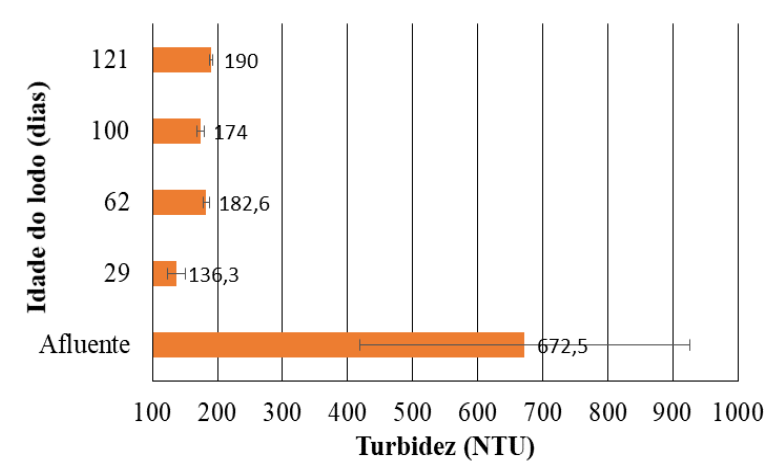

Figura 01 - Monitoramento da turbidez.

De acordo com a figura 01, a turbidez do efluente do reator apresentou pouca variação e se manteve entre 136,3 e 190 NTU, considerando os valores máximos de cada mês avaliado. Observou-se que nos meses de agosto e outubro a turbidez do afluente apresentou valores elevados, 679,3 e 1084 NTU, respectivamente, em relação aos meses de julho e setembro. Esse aumento na turbidez se deve provavelmente pela presença de elevadas concentrações de sólidos em suspensão. Analogamente, nestes dois meses a concentração de sólidos do esgoto bruto também foi alta, ou seja, os sólidos totais são compostos principalmente por sólidos em suspensão ou coloidais.

Notou-se pelos valores de turbidez do efluente que o acúmulo de lodo por 121 dias, não implicou em um elevado arraste de sólidos no reator. Com isso, a turbidez durante todos os meses manteve-se constante, indicando que o lodo ainda pode permanecer no reator.

As resoluções CONAMA $\mathrm{n}^{\circ}$ 357/2005 e 430/2011 não estabelecem valores para este parâmetro, em relação ao lançamento de efluentes. As eficiências de remoção de turbidez durante os quatro meses de operação oscilaram entre 70 a $80 \%$.

$\mathrm{O}$ parâmetro de sólidos totais é frequentemente utilizado para indicar a parcela da biomassa que sai do reator com o efluente final, e também como uma medida da quantidade de matéria orgânica e inorgânica particulada presente no esgoto bruto (Pereira et al., 2010).

Uma elevada concentração de sólidos no efluente do reator UASB pode indicar irregularidades 
operacionais, pela possibilidade de haver arraste de partículas ou excesso de lodo no reator. A perda de sólidos com o efluente tem como consequência o aumento indesejado de DBO e DQO no efluente tratado (Rodrigues et al., 2010).

Conforme a figura 02 , a média da concentração de sólidos totais quantificados no afluente foi de 711,7 mg.L $\mathrm{L}^{-1}$, já no efluente os valores variaram de 315 e $340 \mathrm{mg} . \mathrm{L}^{-1}$.

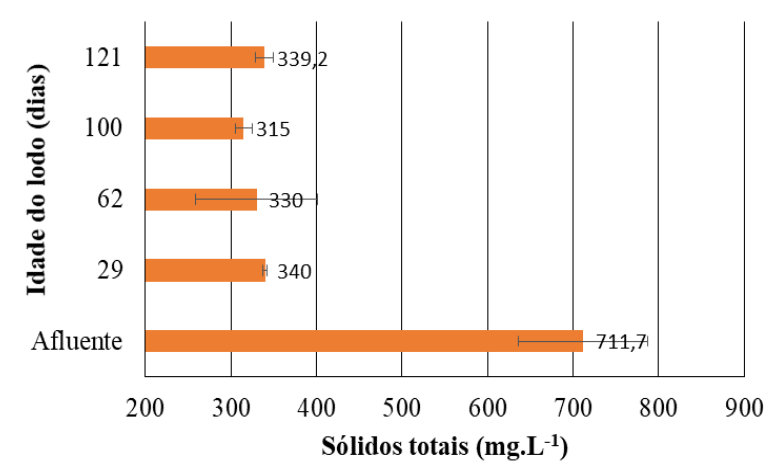

Figura 02 - Média e desvio padrão de sólidos totais no efluente.

De acordo com os dados apresentados na figura 02, a eficiência de remoção de sólidos durante todo o período de monitoramento permaneceu acima de $50 \%$, e para os meses de julho, agosto, setembro e outubro as remoções foram de 52,2 53,6, 55,7 e $52,3 \%$ respectivamente. Segundo Rodrigues et al. (2014), apesar dos reatores UASB conterem um separador trifásico, eles possuem limitação na remoção de sólidos, principalmente quando o afluente recebe alta quantidade de sólidos suspensos.

Durante o período de monitoramento, não foram realizados descartes do lodo do reator e, com base nos valores de sólidos totais obtidos, comparados a idade do lodo de 121 dias, é possível observar que esse parâmetro não foi afetado pelo acúmulo de lodo no reator, visto a variação mínima. Na pesquisa de Verma e Kumar (2013), no qual o reator UASB foi monitorado no tratamento de esgoto doméstico, foram encontrados valores semelhantes de ST no afluente. Von Sperling (1996), ressalta que o esgoto bruto contém uma média de $1000 \mathrm{mg} . \mathrm{L}^{-1} \mathrm{de}$ ST.

As resoluções CONAMA 357/2005 e 430/2011 não definem limites de lançamento para o parâmetro ST, no entanto, Pereira et al. (2010) afirmam que o despejo de efluente com concentrações elevadas de sólidos causa mudança na qualidade do corpo hídrico, pois impedem a passagem de luz, induzem ao aquecimento da água e diminuem a quantidade de oxigênio no meio.

Devido a relação direta entre turbidez e sólidos totais as eficiências de remoção destes dois parâmetros são representadas conjuntamente na figura 03 .

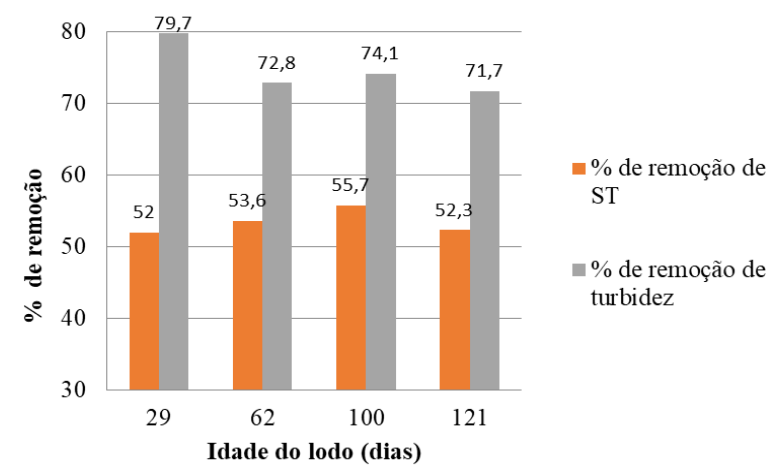

Figura 03 - Eficiência de remoção de sólidos totais e turbidez.

\section{Demanda Bioquímica de Oxigênio}

A eficiência na remoção da matéria orgânica do efluente pode ser observada na Tabela 03 , na qual são apresentados os valores da demanda bioquímica de oxigênio (DBO) do efluente em cada mês avaliado.

$\underline{\text { Tabela } 04 \text { - Concentração e eficiência da remoção de matéria orgânica. }}$

\begin{tabular}{|c|c|c|c|c|}
\hline Período & $\begin{array}{l}\text { Idade do lodo } \\
\quad \text { (dias) }\end{array}$ & $\begin{array}{l}\text { Valor médio } \\
\text { do afluente }\end{array}$ & $\begin{array}{c}\text { Média (mg.L-1 } \text { e }^{-1} \\
\text { Desvio Padrão } \\
\text { (efluente) }\end{array}$ & Eficiência $(\%)$ \\
\hline Julho & $29 n$ & \multirow{4}{*}{$621,7 \pm 168,4$} & $295,3 \pm 5,4$ & 52,5 \\
\hline Agosto & 62 & & $192,6 \pm 11,4$ & 69,0 \\
\hline Setembro & 100 & & $203,3 \pm 9,0$ & 67,3 \\
\hline Outubro & 121 & & $44,3 \pm 6,3$ & 93,0 \\
\hline
\end{tabular}

A média de DBO do afluente foi de $621,7 \mathrm{mg} . \mathrm{L}^{-}$ 1. Após o tratamento, a média da concentração
DBO nos quatros meses apresentou um valor mínimo de 44,3 e máximo de 295,3 mg.. $\mathrm{L}^{-1}$. 
O valor médio de DBO do afluente do reator, obtido neste estudo, encontra-se acima da concentração típica de esgoto bruto, a qual varia de 100 a 400 mg.L $L^{-1}$, segundo Von Sperling (1996). No entanto os resultados são similares aos encontrados por Machado (1997).

Em relação ao efluente, de acordo com a Tabela 02 , os valores obtidos foram acima do reportado por Saliba (2016). Vieira et al. (1992) avaliou reator UASB de ETE experimental localizada em São Paulo e obteve valor de DBO na ordem de 209 mg. $\mathrm{L}^{-1}$ para o afluente e $85 \mathrm{mg} . \mathrm{L}^{-1}$ para o efluente.

Na Tabela 02 observa-se que as remoções de DBO foram de 52,5, 69, 67,3 e 93\%, respectivamente, para os meses de julho, agosto, setembro e outubro.

Notou-se que no mês de julho, após 29 dias de tempo de detenção do lodo, a eficiência representada pelos valores de DBO mostrou-se baixa (apenas $52,5 \%$ ), inferior ao comumente esperado em reatores UASB. Isso pode ser justificado pelo fato de haver pouca acumulação de biomassa e, consequentemente, baixa atividade microbiana. Com o sucessivo acúmulo de biomassa, a eficiência do reator também aumentou e atingiu 93\%, correspondente ao tempo de 121 dias.

De acordo com Chernicharo (1999), uma das principais vantagens dos reatores UASB é a possibilidade de funcionamento com longos períodos de descarte do lodo. Essa característica permite um elevado tempo de detenção do lodo em seu interior, e, assim, a idade do lodo passa a ser sempre maior que o tempo de detenção hidráulica mantido em operação.

Gomes \& Chernicharo (2005) realizaram o monitoramento de um reator UASB por 15 meses e observaram que o tempo médio de descarte do lodo foi de 90 dias para obtenção de eficiências de 85 a $90 \%$ de remoção de DBO.

Em outro estudo, Rizvi et al. (2014) analisaram a partida (inicialização) e o desempenho de reatores UASB operando sob temperatura entre 17 e $38^{\circ} \mathrm{Ce}$ idade de lodo variando de 60 a 180 dias para tratamento de esgoto doméstico. Eles puderam concluir que o desempenho dos reatores apresentou um aumento da eficiência de remoção de DBO de 61 para $85 \%$ com o aumento idade do lodo e temperatura.

A resolução CONAMA $n^{\circ}$ 357/2005 complementada pela Resolução 430/2011, define que os tratamentos secundários devem atingir um limite máximo de $120 \mathrm{mg} . \mathrm{L}^{-1} \mathrm{e}$ uma eficiência mínima de remoção de $60 \%$ de DBO. Desta foram, constatouse, a partir dos dados da Tabela 03, que apenas no mês de julho, quando o reator estava a operar por 29 dias após o esgotamento, não foi possível atingir a mínima eficiência exigida pela resolução.

\section{Determinação do coeficiente de degradação da matéria orgânica}

A obtenção de um modelo matemático que represente o comportamento do sistema em operação é importante para que sejam realizadas previsões quanto ao desempenho do reator. A figura 04 demonstra a degradação da matéria orgânica conforme uma reação de primeira ordem, onde o eixo y representa a DBO do efluente e o eixo x o tempo de detenção do lodo no reator.

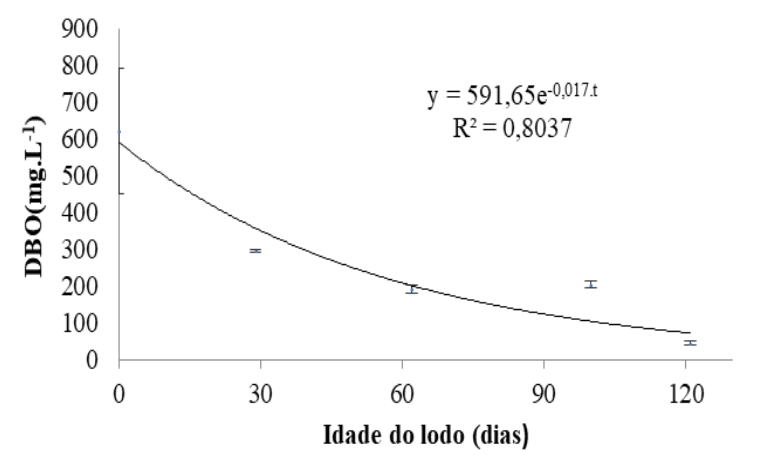

Figura 04 - Modelo de primeira ordem para a remoção de matéria orgânica.

Sendo a equação descrita por:

$$
D B O=591,6 e^{-0,0174 . t}
$$

Onde t é o tempo de detenção do lodo no reator.

Pela equação é possível estimar a eficiência do reator em função da idade do lodo, substituindo $\mathrm{x}$ pelo tempo de detenção do lodo em dias. Esta equação pode ser utilizada para este reator, desde que o afluente esteja com características físico-químicas semelhantes aos apresentados neste estudo.

A constante $\mathrm{k}$ representa a taxa de estabilização bioquímica da matéria orgânica presente no esgoto, a qual foi de 0,0174 d-1. De acordo com Barros Neto et al. in Sartori (2015), o coeficiente de determinação da regressão $\left(\mathrm{R}^{2}\right)$ é definido como a fração da variação total explicada pelo modelo. Assim, quanto maior o R2, ou seja, mais próximo de 1, menor será o erro e melhor será o modelo. Quando o valor do $\mathrm{R}^{2}$ for menor que 0,60 , os modelos só poderão ser utilizados como indicadores de tendências, não podendo ser utilizados para fins preditivos.

$O$ coeficiente de determinação da regressão $\left(R^{2}\right)$ a partir da equação de primeira ordem foi 0,803 , ou seja, o valor obtido para o coeficiente de regressão foi superior a $80 \%$, o que confirma que o modelo cinético de primeira ordem foi adequado para descrever a degradação da matéria orgânica no reator. 
No entanto, não é descartada a possibilidade de usar outro modelo que se ajuste melhor ao desempenho do reator.

Neste contexto, o modelo adaptado por Spline Cúbica oferece o melhor ajuste aos resultados experimentais, apresentando um $\mathrm{R}^{2}$ superior a 0,99 (Figura 5).

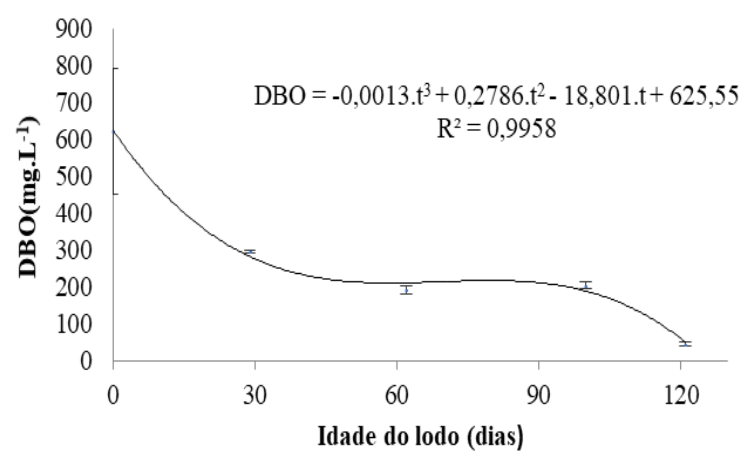

Figura 05 - Modelo ajustado por Spline Cúbica para a remoção de matéria orgânica.

Sendo a equação descrita por:

$$
\begin{gathered}
D B O=-0,0013 \cdot t^{3}+0,2786 \cdot t^{2}-18,801 \cdot t \\
+625,55
\end{gathered}
$$

Onde t é o tempo de detenção do lodo no reator.

\section{CONCLUSÕES}

A análise dos parâmetros físico-químicos permitiu verificar que, de forma geral, a ETE está com um bom desempenho operacional. $\mathrm{O} \mathrm{pH}$ tanto do afluente como efluente apresentaram valores semelhantes, próximo da neutralidade e adequados para o processo anaeróbio. A remoção de turbidez foi eficiente atingindo uma média geral acima de $70 \%$.

Para sólidos totais, a média de eficiência em todos os meses foi próxima de $50 \%$.

O reator UASB apresentou uma eficiência média de remoção de DBO acima de $70 \%$, portanto, a eficiência condiz com a faixa de remoção descrita na literatura para reatores UASB e está de acordo com o valor estabelecido pelo CONAMA (Resoluções 357/2005 e 430/2011).

Com o monitoramento foi possível obter dados importantes para a otimização do sistema, pois o reator apresentou capacidade de operar por no mínimo quatro meses sem o esgotamento do lodo, o que acarreta na melhoria do sistema de tratamento como também na maior estabilidade do lodo retirado do reator.

Nas condições do experimento pode se concluir que a velocidade de degradação da matéria orgâ- nica no reator UASB em estudo, pode ser representada por uma reação de primeira ordem, mas tem melhor ajuste pelo modelo adaptado por Spline Cúbica.

\section{REFERÊNCIAS BIBLIOGRÁFICAS}

ABDELGADIR, A.; CHEN, X.; LIU, J.; XIE, X.; ZHANG, K.; WANG, H.; LIU, N. Characteristics, process parameters, and inner components of anaerobic bioreactors. Bio Med Research International, v.2014, 2014. http://dx.doi.org/10.1155/2014/841573

ALVES, I. Caracterização de grânulos de reator UASB empregado no processamento de vinhaça. Ano de obtenção: 2015. 85 p. Dissertação (Mestrado em Ciências: Engenharia Hidraúlica e Saneamento) - Universidade de São Paulo, São Carlos.

APHA, A.W.W.A. WEF. Standard methods for the examination of water and wastewater, v.22, 1496p. 2012.

ARAGÃO, P. E. A. Análise sobre métodos de estimativa de parâmetros cinéticos em ensaio de degradação de matéria orgânica. Ano de obtenção: 2016. 70 p. Dissertação (Mestrado em Engenharia Civil) - Universidade Federal do Ceará, Fortaleza.

BRASIL, I. T. Ranking do Saneamento, 2019. Acesso em: 22 de out. 2019.

BRASIL, Conselho Nacional de Meio Ambiente. Resolução no 357. Dispõe sobre a classificação dos corpos de água e diretrizes ambientais para o seu enquadramento, bem como estabelece as condições e padrões de lançamento de efluentes, e das outras providencias. Disponível em:

http://www.mma.gov.br/port/conama/legiabre.cfm?codlegi $=459$. Acesso em: 7 de set. 2017

BRASIL, Conselho Nacional de Meio Ambiente. Resolução no 430. Dispõe sobre condições e padrões de lançamentos de efluentes, complementa e altera a Resolução no 357, de 17 de março de 2005. Disponível em:

http://www.mma.gov.br/port/conama/legiabre.cfm?codlegi=646. Acesso em: 28 de ago. 2017.

CHERNICARO, C.A.L.; VAN HAANDEL, A.; AISSE, M.M.; CAVALCANTI, P.F.F. Capítulo 7, Reatores Anaeróbios de Manta de Lodo. Tratamento de esgotos sanitários por processo anaeróbio e disposição controlada no solo. PROSAB, ABES, Rio de Janeiro, cap.7, p.155-198, 1999.

FORESTI, E. Anaerobic treatment of domestic sewage: established technologies and perspectives. Water Science and Technology, v. 45, n. 10, p. 181-186, 2002.

https://doi.org/10.2166/wst.2002.0324

FORESTI, E.; LOURDINHA, F.; VAN HAANDEL, A.; ZAIAT, M.; CAVALCANTI, P.F.F. Fundamentos do tratamento anaeróbio. PROSAB, ABES, Rio de Janeiro, cap.2, p.29-52,1999.

GOMES, M.R; CHERNICHARO, C.A.D.L. Experiência operacional e análise de desempenho do sistema de tratamento de esgotos de Bonito-MS. In: Congresso Brasileiro de Engenharia Sanitária e Ambiental, 23. ABES, 2005. p.1-10.

IBGE, Instituto Brasileiro de Geografia e Estatística, 2019, São Paulo. 
LEITÃO, R.C; VAN HAANDEL, A.C; ZEEMAN, G.; LETTINGA, G. The effects of operational and environmental variations on anaerobic wastewater treatment systems: a review. Bioresource technology, v.97, n.9, p.1105-1118, 2006.

https://doi.org/10.1016/j.biortech.2004.12.007

LIMA, A.B.B.V. Pós-Tratamento de efluente de reator anaeróbio em sistema sequencial constituído de ozonização em processo biológico aeróbio. Ano de obtenção: 2016. 83 p. Dissertação (Mestrado em Saneamento e Hidráulica) - Universidade de São Paulo, São Carlos, 2006.

LINS, G.A. Impactos ambientais em estações de tratamento de esgotos (ETE's). Ano de obtenção: 2010. 286p. Dissertação (Mestrado em Engenharia Ambiental) - Universidade Federal do Rio de Janeiro, Rio de Janeiro.

MACHADO, R.M.G. Estudo da associação em série de reator UASB e filtros anaeróbios para o tratamento de esgotos sanitários. Ano obtenção: 1997. 165p. Dissertação (Mestrado em Saneamento, Meio Ambiente e Recursos Hídricos) - Universidade Federal de Minas Gerais, Belo Horizonte.

NETO, M.S.A. Tratamento de águas residuárias de suinocultura em reator anaeróbio compartimentado seguido de reator UASB. Ano de obtenção: 2007. 170p. Dissertação (Mestrado em Microbiologia Agropecuária) - Universidade Estadual Paulista, Faculdade de Ciências Agrárias e Veterinárias, Jaboticabal.

OLIVEIRA, C.M.R. Aplicabilidade de sistemas simplificados para Estações de Tratamento de Esgoto de cidade de pequeno porte. Ano de obtenção: 2014. 88p. Juiz de Fora, MG. Monografia (Graduação em Engenharia Sanitária e Ambiental) - Universidade Federal de Juiz de Fora, Juiz de Fora.

PENA, J.S.F. Caracterização e tratabilidade do efluente gerado em indústria de refrigerantes empregando reator UASB. Ano de obtenção: 2016. Dissertação (Mestrado em Ciência e Tecnologia de Alimentos) - Instituto Federal de Educação, Ciência e Tecnologia do Triângulo Mineiro.

PEREIRA, E.L.; CAMPOS, C.M.M.; MOTERANI, F. Avaliação do desempenho físico-químico de um reator UASB construído em escala piloto na remoção de poluentes de efluentes de suiconcultuta. Ambi-Agua, v.5, n.1, p.77-88, 2010.

https://doi.org/10.4136/ambi-agua.121

PIVELI, R.P. Curso:“Qualidade das águas e poluição: aspectos físico-químicos". http://www. ebah. com. br/content/ABAAAAPBcAD/fasci culo-10-oxigenio-dissolvidomateria-organica\#>. Acesso em: 22/10/2019. v.21, n.05, p.2015, 2000.

PONTES, P.P.; CHERNICHARO, C.A.L. Efeito do retorno de lodo aeróbio sobre as características da biomassa presente em reatores UASB tratando esgoto sanitário. Eng Sanit Ambient, v.14, n.2, p.223-234, 2009.

RIZVI, H.; AHMAD, N.; ABBAS, F.; BUKHARI, I.H.; YASAR, A.; ALI, S.; YASMEEN, T.; RIAZ, M. Start-up of UASB reactors treating municipal wastewater and effect of temperature/sludge age and hydraulic retention time (HRT) on its performance. Arabian Journal of Chemistry, v.8, p.780-786, 2014.

https://doi.org/10.1016/j.arabjc.2013.12.016
RODRIGUES, L.S.; SILVA, I.J.; ZOCRATO, C.O.M.; PAPA, D.P.; SPERLING, M.V.; OLIVEIRA, P.R. Avaliação de desempenho de reator UASB no tratamento de águas residuárias de suinocultura. Revista Brasileira de Engenharia Agrícola e Ambiental, v.14, n.1. p.94-100, 2010. http://dx.doi.org/10.1590/S1415-43662010000100013

RODRIGUES, L.S.; SPELTA, A.C.F.; SANTOS R.P.; LIMA, C.A.; DUTRA, J.C.F.; SILVA, I.J. Avaliação de reator anaeróbio de manta de lodo (UASB) no tratamento de efluentes de frigorífico. B. Indústr. Anim, Nova Odessa, v.71, n.4, p.365-370, 2014.

SALIBA, P.D. Avaliação do desempenho de sistema de tratamento de esgoto sanitário composto de reator UASB seguido de lodo ativado: estudo de caso da ETE- Betim central-MG. Ano de obtenção: 2016. 159 p. Dissertação (Mestrado em Saneamento, Meio Ambiente e Recursos Hídricos) - Universidade Federal de Minas Gerais, Belo Horizonte, 2016.

SANT'ANNA JUNIOR, G.L. Tratamento biológico de efluentes - Fundamentos e Aplicações. 2ed. Rio de Janeiro: Editora Interciência, 2013.

SARTORI, J.A.S.; MAGRI, N.T.C.; DE AGUIAR, C.L. Clarificação de caldo de cana-de-açúcar por peróxido de hidrogênio: efeito da presença de dextrana/Clarification of sugarcane juice by hydrogen peroxide: effects of the presence of dextran. Brazilian Journal of Food Technology, v.18, n.4, p.299, 2015.

http://dx.doi.org/10.1590/1981-6723.4215

SEGHEZZO, L.; ZEEMAN, G.; VAN LIER, J.B.; HAMELERS, H.V.M.; LETTINGA, G. A review: the anaerobic treatment of sewage in UASB and EGSB reactors. Bioresource technology, v. 65, n. 3, p. 175-190, 1998. https://doi.org/10.1016/S0960-8524(98)00046-7

VERMA, A.K.; KUMAR, S. Characterization of wasteand Project of UASB reactor for its treatment. Ano de obtenção: 2013. 58 p. Tese (Bacharel em Engenharia Civil) Instituto Nacional de Tecnologia Rourkela, Rourkela.

VIEIRA, S.M.M.; CARVALHO, J.L.; BARIJAN, F.P.O, RECH, C.M. Application of the UASB technology for sewage treatment in a small community at Sumare, Sao Paulo State. Water Science \& Technology, v.30, n.12, p.203-210, 1994.

VON SPERLING, M. Introdução à qualidade das águas e ao tratamento de esgotos. Belo Horizonte: Editora UFMG, 243p. 1996. 